\title{
Apontamentos sobre a participação feminina na pesquisa no campo da saúde a partir do acervo de obras raras da Biblioteca de Manguinhos da Fundação Oswaldo Cruz
}

Jeorgina Gentil Rodrigues

Doutora em Informação, Comunicação em Saúde (Fiocruz/Icict).Bibliotecária da Biblioteca de Manguinhos/Instituto de Comunicação e Informação Científica e Tecnológica em Saúde (Icict)/Fundação Oswaldo Cruz

Maria Cristina Soares Guimarães

Doutora em Ciência da Informação (UFRJ/Ibict) Pesquisadora do Icict/Fundação Oswaldo Cruz

http://dx.doi.org/10.1590/1981-5344/2495

Esse artigo pretende discutir a participação feminina na pesquisa no campo da saúde a partir do acervo de obras raras da Biblioteca de Manguinhos do Icict/Fiocruz, sendo as teses inaugurais o primeiro passo para traçar esse caminho. São ainda raras as análises que deem conta do uso e impacto das teses como fonte de informação para pesquisa. Além, pouco se discute sobre os elementos descritivos dessas teses e suas características bibliográficas e bibliológicas enquanto obras raras, o que tem implicações na descrição e organização das mesmas para disponibilizá-las. Essa é a discussão aqui travada, na expectativa que seja possível dar início a descrição de uma trajetória feminina no campo das ciências da saúde a partir da digitalização do material identificado e disponibilização para a comunidade científica, por meio do Repositório Institucional da Fiocruz, o ARCA.

Palavras-chave: Produção científica feminina; Gênero e ciências; Teses inaugurais; Obras raras. 


\section{Notes about the feminine participation in the field of health as from the collection of rare works the Manguinhos Library at the Oswaldo Cruz Foundation}

This article aims to discuss feminine participation in the field of health as from the collection of rare works at the Icict/Fiocruz Manguinhos Library, with the innaugural theses being the first step to plot this path. There are still rare analyses which render account on the use and impact of the theses as source of information for research. Moreover, little is discussed on the descriptive elements of such theses and their bibliographic and bibliological features as rare works, which bear implications upon their description and organization to make them available. This is the discussion carried out here, in the assumption that it be possible to start the description of a feminine path in the field of health sciences as from the digitalization of the material identified, as well as making it available to the scientific community, by means of the Fiocruz Institutional Repository, the ARCA.

Keywords: Women's scientific production; Gender and sciences; Innaugural theses; Rare books.

Recebido em 27.07.2015 Aceito em 11.02.2016

\section{Introdução}

Os primeiros registros referentes às teses inaugurais datam do século XIII, na Itália desde então, estas fontes privilegiadas de produção de conhecimento tem sido utilizada com o propósito de servir à comunidade científica. Uma característica peculiar das teses inaugurais é que serviam como o espelho da produção científica de uma área, em uma determinada época, tendo em vista a representatividade desse tipo de produto no âmbito da produção acadêmica de uma forma geral. Embora nem todas elas contribuam de forma imediata à ciência e à sociedade, as teses inaugurais fazem parte de um esforço de pesquisa e de busca do 
conhecimento que precisa ser compartilhado (DAVINSON, 1977; HAY; MADDOCK, 1981; LARIVIÈRE; ZUCCALA; ARCHAMBAULT, 2008).

O papel mediador das Tecnologias de Informação e Comunicação (TIC's) na construção, organização e disponibilização documental (SANTOS, 2011) abrem a oportunidade de trazer a tona toda uma memória científica da produção de conhecimento por meio das teses inaugurais, na medida em que permitem que essas obras sejam digitalizadas e disponibilizadas de diferentes formas, inclusive por meio dos repositórios institucionais de livre acesso no Brasil.

Especificamente no caso do acervo de obras raras Biblioteca de Manguinhos do Instituto de Comunicação e Informação Científica e Tecnológica em Saúde (Icict), da Fundação Oswaldo Cruz (Fiocruz) existe um conjunto representativo de teses na área de medicina do final do século XIX.

A análise dos aspectos da contribuição das mulheres médicas, ainda que fragmentada, deverá contribuir para um melhor entendimento sobre as condições que influenciaram a presença de mulheres no meio científico no Brasil, na primeira metade do século $X X$, e quais as dificuldades e conquistas envolvidas nesse processo (COLLING, 2011).

Assim, dentro de um grande programa de digitalização de obras raras da Biblioteca de Manguinhos, à luz de uma política de livre acesso, o presente artigo pretende discutir a participação feminina na pesquisa no campo da saúde a partir desse acervo de obras raras, sendo as "Teses Inaugurais", o primeiro passo para delinear essa participação.

\section{As teses inaugurais como fonte de informação}

A institucionalização da medicina acadêmica no Brasil se inicia com a criação das Faculdades de Medicina da Bahia e do Rio de Janeiro (SOUZA; JACÓ-VILELA, 2008). Um requisito formal se apresentava nas faculdades de medicina: para a obtenção da licença profissional era necessário que o aluno em final de curso fizesse um trabalho monográfico, designado por "Tese Inaugural" também designada "Tese de Doutoramento" ou "Dissertação inaugural" e que este fosse defendido publicamente perante uma banca composta por professores do corpo docente (SOUZA; JACÓVILELA, 2008; COSTA, VIEIRA, 2011). Esta prática permaneceu até 1930, quando um decreto federal tornou-a optativa (LHULLIER; MASSIMI, 2006). Segundo Souza e Jacó-Vilela (2008, p. 41), as teses de inaugurais em medicina tornam-se:

[...] eficientes instrumentos de internalização e divulgação de idéias que procuravam balizar a prática médica. Independentemente de serem mais científicas ou ainda voltadas para uma avaliação religiosa ou moral dos assuntos escolhidos como seus temas centrais, o certo é que eram instrumentos de consulta para os estudantes e profissionais, pois serviam como base de experiências anteriores que poderiam nortear as novas práticas. 
Na década seguinte, o número de teses produzidas diminuiu quiçá em consequência da não-obrigatoriedade de apresentação de um trabalho final para a obtenção do diploma e do título de "Doutor". Por outro lado, elas privilegiavam a investigação experimental e tratavam de temas surgidos da prática dos estudantes de medicina nas enfermarias dos hospitais durante a realização do curso (LHULLIER; MASSIMI, 2006).

Observada enquanto fonte de pesquisa, a tese constitui-se num corpus de documento, tanto mais que faz parte de um conjunto de documentos passíveis de serem submetidos a procedimentos analíticos (COSTA; VIEIRA, 2011, p. 11).

As teses inaugurais apresentam-se, assim, como fontes para vários estudos na área de informação para enriquecer a memória científica e tecnológica e, em particular, para estudo da literatura cinzenta ${ }^{1}$.

\section{Participação feminina no campo da saúde}

Em 1808, com a vinda da família real para o Brasil, o príncipe regente D. João criou, por carta régia, as primeiras escolas de ensino superior do país: a Escola de Cirurgia da Bahia e a Escola Anatômica, Cirúrgica e Médica do Rio de Janeiro. Iniciou-se, assim, o processo de institucionalização da medicina no Brasil (CARVALHO; CECCIM, 2006; SOUZA; JACÓ-VILELA, 2008; STARLING; GERMANO; MARQUES, 2011).

Em 1832, as academias do Rio de Janeiro e da Bahia foram transformadas em faculdades, e com isso foram definidas novas mudanças. A duração do curso de medicina passou para 6 anos e o ingresso no curso passou a se dar a partir dos 16 anos. Também estabeleceu-se a obrigatoriedade de exames preparatórios, ampliaram-se os conhecimentos exigidos para a obtenção do título de médico (EDLER; FONSECA, 2000; BRIANI, 2003).

No mesmo ano, a presença das mulheres nas duas Faculdade de Medicina (Bahia e Rio de Janeiro) deu-se inicialmente exclusivamente no então denominado "Curso de Partos", realizado em três anos. As parteiras recebiam ao cabo desses três anos, o título de parteira diplomada. O título de doutor era exclusivo de estudantes do sexo masculino (MOTT, 1999; PORTO; CARDOSO, 2009). O acesso feminino aos cursos acadêmicos demorou a ser autorizado.

Entre 1879, com a Reforma Leôncio de Carvalho que concedeu as mulheres à permissão da diplomação nos diversos cursos de ensino superior em todo Império brasileiro e a obter o título superior, e 1900, cinco mulheres completaram o ensino médico e exerceram a profissão: Rita Lobato Lopes, em 1887; Ermelinda Lopes de Vasconcelos, em 1888; Antonieta Cesar Dias, em 1889; Maria Amélia Cavalcante, em 1889; Judith Adelaide Maurity Santos, em 1900. Antes, Maria Augusta Generoso

\footnotetext{
1 A expressão literatura cinzenta, tradução literal do termo inglês grey literature, é usada para designar documentos não convencionais e semipublicados, produzidos nos âmbitos governamental, acadêmico, da indústria (CAMPELLO; CENDÓN; KREMER, 2000).
} 
Estrela e Josefa Águeda Felisbela Mercedes de Oliveira precisaram sair do país para se formarem nos Estados Unidos, respectivamente em 1881 e 1882 (LIMA, 2002; FRANCO, 1994; 2001; FRANCO; SANTOS, 2010; SILVA; RIBEIRO, 2010).

O caminho foi lento para as primeiras mulheres médicas, com idas e vindas, fases de abertura e outras de retração, além da falta de apoio familiar (e estatal) e preconceitos variados (FRANCO; SANTOS, 2010).

\section{0 acervo de obras raras da Fiocruz}

Em 1900, foi criado o Instituto Soroterápico Federal, origens da Fiocruz. Com a criação do Instituto teve início a formação do acervo bibliográfico da Fiocruz. Muitos títulos faziam parte das coleções particulares dos pesquisadores da instituição (BORTOLETTO; SANT'ANNA, 2002).

Em 1907, o Instituto recebeu a medalha de ouro no XIV Congresso Internacional de Higiene e Demografia de Berlim, pelo trabalho de saneamento do Rio de Janeiro. O impacto da premiação foi decisivo para a ampliação do acervo da Biblioteca (BUSTAMANTE, 1958). Com a notoriedade crescente da Instituição, pesquisadores brasileiros e estrangeiros colaboraram na formação da coleção de teses, através de doações de seus trabalhos acadêmicos.

Em 1908, a instituição passa a denominar-se Instituto Oswaldo Cruz - uma homenagem ao médico sanitarista Oswaldo Cruz (STEPAN, 1976; BENCHIMOL, 1990).

O rápido crescimento experimentado pelo acervo da Biblioteca do Instituto Oswaldo Cruz, atual Biblioteca de Manguinhos, levou Oswaldo Cruz a contratar, em 1909, Assuerus Hyppolitus Overmeer, bibliófilo holandês, para organizar a Biblioteca, onde permaneceu por 35 anos. 0 trabalho desenvolvido por Overmeer consolidou a Biblioteca do Instituto Oswaldo Cruz como uma das primeiras fontes de informação científica no Brasil (SOUSA, 2006).

A questão da qualidade do acervo fica pertinente, sobretudo em relação ao referimento de Araújo Filho (1941, p. 463): "Falar da biblioteca de Manguinhos é evocar esta Instituição. A evolução de ambas se confunde tão intimamente estão ligadas".

Os cientistas do Instituto colaboraram na formação do acervo, cabendo especial destaque a Arthur Neiva, autoridade em entomologia médica, que selecionou os primeiros clássicos das ciências naturais que a Biblioteca deveria adquirir e influiu decisivamente na formação do acervo de obras raras (ARAÚJO FILHO, 1941; ARAGÃO, 1950; RODRIGUES, 1996). Nas palavras de César Pinto: "Ele deu inteligência, interesse e operosidade para formação da grande Biblioteca do Instituto Oswaldo Cruz. [...] é um dos feitos mais brilhantes e menos conhecido de Arthur Neiva" (PINTO, 1932, p. 6).

Atualmente, o acervo de obras raras encontra-se localizado no 30 andar do Pavilhão Mourisco, sede original da Biblioteca do Instituto 
Oswaldo Cruz e conta com cerca de 40 mil volumes, datados a partir do século XVII, distribuídos, grosso modo: 17 mil volumes de livros, 562 títulos de periódicos nacionais e estrangeiros, com aproximadamente 15 mil volumes, 3 mil volumes de teses inaugurais e de doutoramento e 5 mil volumes de materiais diversos (folhetos, manuscritos e iconografia). Tomase essa coleção como objeto para iniciar a identificação e descrição das teses de medicina redigidas por mulheres brasileiras.

A escolha desse acervo se deu pelo prestígio da Fiocruz no cenário científico nacional e pelo fato de dispor de uma biblioteca que conta com um acervo de obras raras que se constitui como uma memória científica ímpar no país (BORTOLETTO; SANT'ANNA, 2002), e se apresenta como fonte privilegiada para estudos de várias naturezas no campo da Ciência da Informação.

Dar visibilidade a produção acadêmica feminina, com foco em um conjunto de teses inaugurais que data ainda do século XIX, deve contribuir também para enriquecer a memória em ciência e tecnologia em saúde no Brasil, e abrir nova fonte de estudo para outros campos do saber.

\section{Pesquisa empírica do material que consta das teses mapeadas}

Para este estudo, foram mapeadas as teses de medicina redigidas por mulheres brasileiras pertencente ao acervo de obras raras da Biblioteca de Manguinhos.

O levantamento se deu devido à necessidade de obter uma amostra da produção acadêmica feminina.

O critério utilizado para este mapeamento originou-se das próprias teses que traziam, em sua folha de rosto, a disciplina na qual foram elaboradas. O material investigado cobriu um período que vai de 1900 até a década de 1930, período de transição do perfil educacional feminino que evolui do analfabetismo para formação em nível superior e promoveu a inserção profissional de mulheres no mundo acadêmico e científico (AZEVEDO; FERREIRA, 2006).

Azevedo e Ferreira (2006, p. 217) constatam que a partir da década de 1920 as experiências de escolarização em nível superior, proporcionada pelas políticas sociais e educacionais implantadas, foram às medidas responsáveis por importantes mudanças no sistema de gênero, que efetivamente se institucionalizaram no Estado Novo (1930-1945), especialmente no que diz respeito à inserção profissional de mulheres em carreiras científicas que até então se constituíam em "um monopólio masculino".

O mapeamento iniciou-se a partir da ordenação das teses em ordem cronológica. Concluído esse momento, as teses identificadas como de autoria feminina foram retiradas das estantes e anotadas em uma planilha. O mapeamento levou cerca de três meses e contou com a 
colaboração de um bolsista de nível superior. Realizou-se também um diagnóstico superficial do estado de conservação das teses.

$O$ quantitativo de teses redigidas por mulheres (brasileiras e estrangeiras) no acervo de obras raras é ainda muito modesto se comparado à produção masculina, não passando de $1,7 \%$ do total da coleção. A maior titulação masculina em número absoluto fica evidente: 2.950 teses redigidas por homens e 50 teses redigidas por mulheres. 0 percentual das teses de autoria feminina representa um valor menor que $1,7 \%$ do total da coleção teses do acervo de obras raras. As teses redigidas por mulheres estrangeiras não são o objeto da presente análise.

Das 50 teses inaugurais ou de doutoramento redigidas por mulheres, 20 teses eram redigidas por mulheres brasileiras e 30 teses eram redigidas por mulheres estrangeiras. É importante salientar que as 20 teses redigidas por mulheres brasileiras constituíram o objeto de estudo do presente artigo. As teses redigidas por estrangeiras não foram utilizadas neste estudo, pois se afastavam do objetivo proposto.

As teses mapeadas foram analisadas a partir da aplicação da norma $\operatorname{ISBD}(M)$ : descrição bibliográfica internacional normalizada das publicações monográficas (International Standard Bibliographic Description for Monographic Publications) ${ }^{2}$. Foram considerados os seguintes elementos e fontes de informação: título e autoria (página de rosto), imprenta (página de rosto, outras preliminares, colofão ${ }^{3}$, descrição física (a própria publicação), notas (qualquer fonte), estado de conservação (item em mãos). Segue-se assim, o registro descritivo para cada uma das 20 teses encontradas:

SANTOS, Judith Adelaide Maurity. Evolução therapeutica: proposições: três sobre cada uma das cadeiras da Faculdade. 1900. Tese de doutoramento (cadeira de therapeutica) - Faculdade de Medicina e de Pharmacia do Rio de Janeiro. Rio de Janeiro: Typ. Leuzinger, 1901. 148 p.: front.; $27 \mathrm{~cm}$.

Notas:

"Approvada com distincção" (Cf. página de rosto).

Inclui um frontispício com retrato da autora.

Inclui errata.

Inclui nota de rodapé.

Citação de nomes ao longo do texto, sem nenhuma referência bibliográfica ao final.

Estado de conservação do exemplar: capa, contracapa, folha de rosto e primeiras folhas soltas.

TORRES, Ursulina Lopes. Semiologia do feixe de His (do bloqueio cardíaco). 1908. Tese de doutoramento (cadeira de clinica propedeutica) - Faculdade de Medicina do Rio de Janeiro. Rio de Janeiro: Typ. do Jornal do Commercio, 1908. 104 p.: il., fot., estampas; $26 \mathrm{~cm}$.

Notas:

Folhas de estampas intercaladas sem numeração.

Citação de nomes ao longo do texto, com referência no rodapé.

Ex-dono na página de rosto: "J. Fonseca".

Estado de conservação do exemplar: folha de rosto solta.

SANTOS, Maria Fausta dos. Pleuriz bloqueado. 1914. Tese inaugural (cadeira de clinica medica) - Faculdade

\footnotetext{
${ }^{2}$ A ISBD $(M)$ está limitada às publicações editadas depois de 1881 (inclusive), em que o texto e/ou as ilustrações são visíveis a olho nu, por exemplo, livros impressos (FEDERAÇÃO INTERNACIONAL DE ASSOCIAÇÕES DE BIBLIOTECÁRIOS E INSTITUIÇÕES - IFLA, 2005).

${ }^{3}$ Colofão: dados de impressor, local e data da impressão, em geral, registrados no final da obra (Nota das Autoras).
} 
de Medicina do Rio de Janeiro. Rio de Janeiro: Typ. Misericórdia, 1914. 60 p.; 27 cm.

Notas:

"Approvada com distinç̧ão" (Cf. página de rosto).

Citação de nomes ao longo do texto, sem nenhuma referência acerca da obra.

Inclui errata.

Estado de conservação do exemplar: adequado.

PEDROSO, Nathalia de Lima. Como de deve tratar o mal de Pott? 1915. Tese inaugural (cadeira de clinica pediatrica, cirurgica e orthopedica) - Faculdade de Medicina do Rio de Janeiro. Rio de Janeiro: Typ. do Jornal do Commercio, 1915. 106 p.; $27 \mathrm{~cm}$.

Notas:

"Approvada com distincção" (Cf. página de rosto).

Inclui errata.

Citação de nomes ao longo do texto, sem nenhuma referência acerca da obra.

Estado de conservação do exemplar: capa e contracapa soltas.

PEDROSO, Etelvina de Lima. O Sporotrichum de Beurmann e suas localisações na mucosa naso-pharyngéa. 1916. Tese inaugural (cadeira de historia natural) - Faculdade de Medicina do Rio de Janeiro. Rio de Janeiro: Typ. Leuzinger, 1916. 120 p.: il., estampas; $26 \mathrm{~cm}$.

Notas:

Citação de nomes ao longo do texto, com bibliografia contendo os nomes citados e outros não citados no texto.

Inclui índice (sumário).

Inclui errata.

Folhas de estampas intercaladas sem numeração.

Estado de conservação do exemplar: adequado.

WATZL, Maria da Gloria. Do pulso na gravidez. 1916. Tese de doutoramento (cadeira de clinica obstetrica) Faculdade de Medicina do Rio de Janeiro, [Rio de Janeiro]. Nictheroy: Typ. Serra Nova, 1916. 58 p. : il., graf., tab.; $26 \mathrm{~cm}$.

Notsa:

"Approvada com distincção" (Cf. página de rosto).

"ex-interna da Maternidade Laranjeiras" (Cf. página de rosto).

Citação de nomes ao longo do texto, com bibliografia contendo os nomes citados e outros não citados no texto.

Inclui índice (sumário).

Estado de conservação do exemplar: papel acidificado.

FIGUEIREDO, Jandyra. Considerações sobre a Coxalgia. 1920. Tese de doutoramento (cadeira de pediatria cirurgica) - Faculdade de Medicina do Rio de Janeiro. Rio de Janeiro: Typ. Ideal, 1920. 58p.; $26 \mathrm{~cm}$.

Notas:

Citação de nomes ao longo do texto, sem nenhuma referência acerca da obra.

Inclui errata.

Estado de conservação do exemplar: papel acidificado.

MOURA, Guiomar Vieira. Da morte fulminante nas cardiopathias. 1920. Tese de doutoramento (cadeira de clinica medica) - Faculdade de Medicina do Rio de Janeiro. Rio de Janeiro: Typ. Baptista de Souza, 1920. 32p.; $26 \mathrm{~cm}$.

Notas:

Citação de nomes ao longo do texto, sem nenhuma referência acerca da obra.

Estado de conservação do exemplar: adequado.

GONZAGA, Beatriz. Da albumino-precipitação (generalidades). 1922. Tese de doutoramento (cadeira de microbiologia) - Faculdade de Medicina do

Notas:

"Approvada com distincção" (Cf. página de rosto).

Citação de nomes ao longo do texto, sem nenhuma referência acerca da obra.

Estado de conservação do exemplar: adequado. 
QUEIROZ, Carlota Pereira de. Estudos sobre o câncer (indagações clinicas e experimentae). 1926. Tese de doutoramento (cadeira de clinica medica) - Faculdade de Medicina do Rio de Janeiro. Rio de Janeiro: Typ. do Jornal do Commercio, 1926. 273 p. : il., estampas; $27 \mathrm{~cm}$.

Notas:

"Prêmio Miguel Couto" (Cf. página de rosto).

Citação de nomes ao longo do texto, com bibliografia contendo os nomes citados e outros não citados no texto.

Folhas de estampas intercaladas sem numeração.

Dedicatória manuscrita a tinta da autora "Ao presado collega Dr. Gustavo de Oliveira Castro, offerece Carlota Pereira de Queiroz. Rio 1927”, na folha de dedicatória.

Estado de conservação do exemplar: capa, contracapa e folha de rosto soltas.

SILVA, Adalgisa Amanda da Fonseca e. A influência da Religião na moral da mulher. 1926. Tese de doutoramento (cadeira de phychiatria) - Faculdade de Medicina do Rio de Janeiro, [Rio de Janeiro]. Ribeirão Preto: Typ. Barillari, 1926. 103p.; $25 \mathrm{~cm}$.

Notas:

Citação de nomes ao longo do texto, com bibliografia contendo os nomes citados e outros não citados no texto.

Estado de conservação do exemplar: adequado.

COSTA, Pauline Vieira da. Appendicites e annexites. 1926. Tese inaugural (cadeira de clinica gynecologica) - Faculdade de Medicina do Rio de Janeiro. Rio de Janeiro: Officina Industrial Graphica, 1926. 33p.; 25 cm.

Notas:

"Approvada com distincção" (Cf. página de rosto).

Citação de nomes ao longo do texto, sem nenhuma referência acerca da obra.

Estado de conservação do exemplar: adequado.

WEINMANN, Aída Gamarra. Acidose na infancia. 1926. Tese de doutoramento (cadeira de clinica pediatrica) - Faculdade de Medicina do Rio de Janeiro. Rio de Janeiro: Pap. Moderna, 1926. 62p.; 26 cm.

Notas:

"Approvada com distincção" (Cf. página de rosto).

Citação de nomes ao longo do texto, com bibliografia contendo os nomes citados e outros não citados no texto.

Inclui errata.

Estado de conservação do exemplar: adequado.

CONCEIÇÃO, Aurora. Therapeutica pelos raios ultra-violeta. 1927. Tese de doutoramento (cadeira de therapeutica) - Faculdade de Medicina do Rio de Janeiro, [Rio de Janeiro]. Ribeirão Preto: Typ. Barillari, 1927. 68 p.; $25 \mathrm{~cm}$.

Notas:

"Approvada com distincção" (Cf. página de rosto).

Citação de nomes ao longo do texto, com bibliografia contendo os nomes citados e outros não citados no texto.

Inclui índice (sumário)

Estado de conservação do exemplar: capa solta.

PEIXOTO, Josephina. A frequencia do Glaucoma na raça negra na Bahia. 1929. Tese de doutoramento (cadeira de ophtalmologia) - Faculdade de Medicina da Bahia, [Salvador]. Bahia: Typ. da Era Nova, 1929. $82 \mathrm{p}$; $27 \mathrm{~cm}$.

Notas:

"Doutora em Sciencias Medico-Cirurgicas" (Cf. página de rosto).

Citação de nomes ao longo do texto, sem nenhuma referência acerca da obra. Inclui errata.

Estado de conservação do exemplar: papel acidificado.

LEITE, Nair. Novas vistas sobre a capacidade funccional do coração. 1931. Tese de doutoramento (cadeira de clinica propedeutica) - Faculdade de Medicina do Rio de Janeiro. Rio de Janeiro: Grafica Ypiranga, 1931. 86p.; $26 \mathrm{~cm}$.

Notas:

"Approvada com distincção" (Cf. página de rosto).

Citação de nomes ao longo do texto, sem nenhuma referência acerca da obra. 
Inclui errata.

Estado de conservação do exemplar: adequado.

PITTA, Hercilia Rocha. Do reflexo pilomotor e sua pesquisa nas doenças nervosas. 1931. Tese inaugural (cadeira de neurologia) - Faculdade de Medicina da Bahia, [Salvador]. Rio de Janeiro: Graphica Sauer, 1931. 88p. : il., fot., estampas; $25 \mathrm{~cm}$.

Notas:

"Approvada com distincção" (Cf. página de rosto). Citação de nomes ao longo do texto, com bibliografia contendo os nomes citados e outros não citados no texto.

Inclui errata.

Folhas de estampas intercaladas sem numeração.

Estado de conservação do exemplar: adequado.

CONCEIÇÃO, Olga Lydia da. Da lactose e sua dosagem (subsidio ao estudo sanitário do leite). 1932. Tese de doutoramento (cadeira de higiene) - Faculdade de Medicina da Bahia, [Salvador]. Bahia: G. Loureiro, 1932. 102 p.: tab.; $27 \mathrm{~cm}$.

Notas:

Citação de nomes ao longo do texto, com referência no rodapé.

Estado de conservação do exemplar: adequado.

AZEVEDO, Emma. Contribuição para o estudo do peso e da estatura das creanças em São Paulo. 1932. Tese de doutoramento (cadeira de clinica pediatrica) - Faculdade de Medicina de São Paulo. São Paulo: Tip. M. E. Silva, 1932. 90 p.: graf., tab.; $23 \mathrm{~cm}$.

Notas:

"Approvada com distincção" (Cf. página de rosto).

Apresenta Banca Examinadora (Cf. folha de rosto).

Citação de nomes ao longo do texto, com bibliografia contendo os nomes citados e outros não citados no texto.

Estado de conservação do exemplar: adequado.

ROMANO, Lucinda. Pesquisa e Dosagem de iodo na Matéria Orgânica pelo método de

Milward. 1933. Tese de doutoramento (cadeira de medicina legal) - Faculdade de Medicina de São Paulo.

São Paulo: Typ. Asbahr, 1933. 40 p.: il., fot., estampas; 24 cm.

Notas:

Citação de nomes ao longo do texto, com bibliografia contendo os nomes citados e outros não citados no texto.

Folhas de estampas intercaladas sem numeração.

Estado de conservação do exemplar: capa e contracapa soltas.

\section{Primeiros resultados}

Em relação aos aspectos bibliográficos (a tese como fonte de informação), a época não existia uma exigência das instituições de ensino superior em seguir um modelo ou padrão de apresentação de monografias. Isso só ocorreu após a Segunda Guerra Mundial, como resultado da chamada 'explosão da informação', e consequentemente, a necessidade de controle do grande fluxo informacional, como a normalização das publicações técnico-científicas. Contudo, o mais importante é que a tese inaugural representava no pensamento médico da época.

Conforme Meadows (1999, p. 30) a falta de "normalização bibliográfica" produzia documentos incompletos, que acabavam por omitir dados importantes das pesquisas, e que muitas vezes geravam a impossibilidade de localizar informações e identificar pesquisas em desenvolvimento. 
A adoção de padrões normativos para a elaboração de qualquer tipo de trabalho científico facilita a sua posterior divulgação para a comunidade científica. Segundo Crespo e Rodrigues (2001, p. 41) a "normalização não é um conceito novo, pois sempre foi necessário determinar princípios que padronizassem alguns aspectos da vida em sociedade e que permitissem sua continuidade". Estes princípios evoluíram em consonância com as necessidades e demandas da sociedade. A adoção constante da normalização nos mais variados aspectos é comprovada inclusive impulsionando o desenvolvimento das TIC.

As teses inaugurais não seguiam uma norma de apresentação. Sendo obrigatória, a tese era um trabalho monográfico apresentado impresso pelo aluno no final do curso para a obtenção da licença profissional e estava sujeita a apresentação e avaliação perante uma banca examinadora constituída por professores do corpo docente. A tese versava sobre um assunto escolhido pelo(a) aluno(a) e relacionado a uma das cadeiras cursadas. Das 20 teses analisadas, apenas uma apresentou o nome dos docentes que constituíam a banca examinadora.

Conforme Lima (1984 ${ }^{4}$ apud BOCHNER, 2012, p. 25), a análise de citações permite verificar o que foi publicado em determinado corte da literatura e relacionar o citante com o citado, dirigindo o leitor para outras fontes de informações correlatas.

Corroborando com o estudo de Bochner (2012, p. 87-89), na análise do padrão de citação adotado nas teses analisadas observou-se que as citações a trabalhos alheios eram feitas no texto de forma bibliograficamente desestruturada. Foi possível identificar formas distintas de citar que foram se modificando e se aprimorando ao longo do tempo.

Constataram-se as seguintes maneiras usadas pelas autoras para realizar citações: 1) Citação de nomes ao longo do texto, sem nenhuma referência acerca da obra; 2) Citação de nomes ao longo do texto, com referência no rodapé; 3) Citação de nomes ao longo do texto, com referência no próprio texto; 4) Citação de nomes ao longo do texto, com referências e bibliografia correspondente.

Em termos bibliológicos ${ }^{5}$ (a tese como informação), as marcas de propriedade (assinaturas, ex-libris, ex-dono, carimbos, brasões, anotações e autógrafos do autor e/ou do possuidor da obra etc.), além de individualizem o exemplar, podem revelar as redes de sociabilidade das autoras.

Pelo mapeamento realizado, encontrou-se em duas teses a presença efetiva (e reduzida) de leitores, constatada pela presença de marca de leitura: ex-dono (notação manuscrita que identifica o dono do exemplar) e dedicatória. Estas marcas de leitura podem ser consideradas como um ato de apropriação do possuidor do exemplar examinado (CUNHA, 2012).

Não se evidenciou rastros de práticas leitoras caracterizados pela presença de outras marcas de leitura como anotações nas margens,

4 LIMA, R. C. M. Estudo bibliométrico: análise de citações no periódico "Scientometrics". Ci. Inf., Brasília, v. 13, n. 1, p. 57-66, jan./jun. 1984.

${ }^{5}$ A Análise Bibliológica permite arrolar todas as informações intrínsecas e extrínsecas (HOUAISS, 1983), originais ou acrescentadas a obra rara, segundo terminologia específica e consagrada. 
carimbos dos proprietários e/ou locais de compra e assinaturas manuscritas nas teses examinadas (AZEVEDO; LINO, 2010). Pelo contrário, algumas teses mantêm páginas que não foram abertas (caderno fechado), o que indica que nunca foram consultadas.

Não foram localizados "objetos-relíquia" (flores secas, fotografias, bilhetes etc.) esquecidos e depositados dentre as páginas das teses examinadas. Conforme Cunha (2012, p. 24) são evidências da passagem do leitor pela publicação e parecem apontar as relações íntimas, complexas e delicadas entre eles.

Em relação ao estado de conservação, observando-se danos causados pelo tempo, as teses analisadas apresentam um estágio de degradação preocupante, ou seja, folhas com papel acidificado (quebradiço) e algumas teses apresentavam a capa, contracapa, folha de rosto e primeiras folhas de texto soltas.

\section{Considerações finais}

Tomar o acervo de obras raras da Biblioteca de Manguinhos, ainda pouco estudado, como ponto de partida para delinear a contribuição acadêmica feminina no esforço de pesquisa em saúde é o tema central do artigo aqui relatado.

São ainda raras as análises que deem conta do uso e impacto das teses como fonte de informação para pesquisa. Além, pouco se discute sobre os elementos descritivos dessas teses e suas características bibliográficas e bibliológicas enquanto obras raras, o que tem implicações na descrição e organização das mesmas para disponibilizá-las.

A expectativa é que seja possível dar início a descrição de uma participação feminina no campo das ciências da saúde a partir da digitalização do material identificado e disponibilização para a comunidade científica, por meio do Repositório Institucional da Fiocruz, o ARCA.

Dar visibilidade a produção acadêmica feminina, com foco em um conjunto de teses inaugurais que data ainda do século XIX, deve contribuir também para enriquecer a memória em ciência e tecnologia em saúde no Brasil, e abrir nova fonte de estudo para outros campos do saber.

\section{Referências}

ARAGÃO, H. B. Notícia histórica sôbre a fundação do Instituto Oswaldo Cruz (Instituto de Manguinhos). Mem. Inst. Oswaldo Cruz, Rio de Janeiro, v. 48 , p. 1-50, 1950.

ARAÚJO FILHO, M. A biblioteca do Instituto Oswaldo Cruz. Rev. Brasil. Biol., Rio de Janeiro, v.1, n. 4, p. 463-466, 1941.

AZEVEDO, N.; FERREIRA, L. O. Modernização, políticas públicas e sistema de gênero no Brasil: educação e profissionalização feminina entre as décadas de 1920 e 1940. Cad. Pagu, Campinas, n. 27, p. 213-254, jul./dez. 2006. 
AZEVEDO, F. C.; LINO, L. A. S. O Inventário da Biblioteca Lélio Gama: recuperação da memória e relevância para estudos afins. An. Bibl. Nac., Rio de Janeiro, v. 128, p. 219-230, 2010. Disponível em: <http://objdigital.bn.br/acervo_digital

/anais/anais_128_2008.pdf>. Acesso em: 19 jul. 2015.

BENCHIMOL, J. L. (Coord.). Manguinhos de sonho à vida: a ciência da Belle époque. Rio de Janeiro: COC/Fiocruz, 1990.

BOCHNER, R. A obra científica de Vital Brazil: influências e relações. Rio de Janeiro: Ibict, 2012. (Relatório de Pós-Doutorado).

BORTOLETTO, M. E.; SANT'ANNA, M. A. A história e o acervo das obras raras da Biblioteca de Manguinhos. Hist. cienc. saúde-Manguinhos, Rio de Janeiro, v. 9, n. 1, p. 187-203, 2002.

BRIANI, M. C. História e construção social do currículo na educação médica: a trajetória do curso de medicina da Faculdade de Ciências Médicas da UNICAMP. 2003. 226f. Dissertação (Mestrado em Educação) Universidade Estadual de Campinas, Campinas, 2003.

BUSTAMANTE, E. M. As bibliotecas especializadas como fontes de orientação na pesquisa científica. Rio de Janeiro: Instituto Oswaldo Cruz, 1958.

CAMPELLO, B S.; CENDÓN, B.V.; KREMER, J. M. (Org.). Fontes de informação para pesquisadores e profissionais. Belo Horizonte: Ed. UFMG, 2000. (Aprender).

CARVALHO, Y. M.; CECCIM, R. B. Formação e educação em saúde: aprendizados com a saúde coletiva. São Paulo: Hucitec; Rio de Janeiro: Fiocruz, 2006.

COLLING, A. M. As primeiras médicas brasileiras: mulheres à frente de seu tempo. Fronteiras, Dourados, MS, v. 13, n. 24, p. 169-183, jul./dez. 2011.

COSTA, R. M. P; VIEIRA, I. As teses inaugurais da Escola Médico-cirúrgica do Porto (1827-1910): uma fonte histórica para a reconstrução do saber médico. $2012 . \quad$ Disponível em: <http://www4.fe.uc.pt/aphes31/papers/sessao_3b/rui_costa_paper.pdf>. Acesso em: 21 nov. 2012.

CRESPO, I. M.; RODRIGUES, A. V. F. Normas técnicas e comunicação científica: enfoque no meio acadêmico. Rev. Dig. Bibl. Ci. Inf., Campinas, v. 9 , n. 1, p. 36-55, jul./dez. 2011. Disponível em: <http://polaris.bc.unicamp.br/seer/ojs/index.php/sbu_rci/article/view/478 $>$. Acesso em: 10 jun. 2013.

CUNHA, M. T. S. Rastros de leituras: um estudo no acervo de livros do Museu da Escola Catarinense (décadas de 20 a 60 do século XX). Educação, Porto Alegre, v. 35, n. 1, p. 18-27, jan./abr. 2012. 
DAVINSON, D. The theses and dissertations: as information sources. London: C. Bingley, 1977.

EDLER, F. C.; FONSECA, M. R. F. 2006 História da educação médica no Brasil. Cadernos da ABEM, Rio de Janeiro, v. 2, p. 8-27, 2006.

ESCOLA Anatômica, Cirúrgica e Médica do Rio de Janeiro. Dicionário Histórico-Biográfico das Ciências da Saúde no Brasil (1832-1930). Disponível em: <http://www.dichistoriasaude.coc.fiocruz.br.>. Acesso em: 28 jun. 2012.

FRANCO, T. Doutora Judith, a primeira mulher médica formada no Rio de Janeiro: uma crônica emocionada. An. Acad. Nac. Med., Rio de Janeiro, v. 154, n. 1, p. 42-45, 1994.

FRANCO, T. R. Médicas Pioneiras. In: GOMES, M. M.; VARGAS, S. S. M.; VALLADARES, A. F. A Faculdade de Medicina Primaz do Rio de Janeiro: em dois dos cinco séculos de história do Brasil. Rio de Janeiro: Atheneu, 2001. p. 44-52.

FRANCO, T.; SANTOS, E. G. Mulheres e cirurgiãs. Rev. Col. Bras. Cir., Rio de Janeiro, v. 37, n. 1, p. 72-077, 2010.

FEDERAÇÃO INTERNACIONAL DE ASSOCIAÇÕES DE BIBLIOTECÁRIOS E INSTITUIÇÕES - IFLA. ISBD(M): descrição bibliográfica internacional normalizada das publicações monográficas. Lisboa: Biblioteca Nacional / JOSTIS, $2005 . \quad$ Disponível em: <http://pt.scribd.com/doc/23586599/Descricao-BibliograficaInternacional-Normalizada-Monografias>. Acesso em: 10 jan. 2013.

HAY, A. M.; MADDOCK, S. The contribution of postgraduate thesis research to the published literature of human geography in the UK. Social Science Information Studies, v. 1, p. 165-172, 1981.

HOUAISS, A. Elementos de bibliologia. Reimpressão fac-similar. São Paulo: HUCITEC; Brasília: INL/Fundação Nacional Pró-Memória, 1983.

LARIVIERE, V.; ZUCCALA, A.; ARCHAMBAULT, E. The declining scientific impact of theses: implications for electronic thesis and dissertation repositories and graduate studies. Scientometrics, v. 74, n. 1, p. 109-121, 2008.

LHULLIER, C.; MASSIMI, M. Psicologia nas teses da Faculdade de Medicina de Porto Alegre. In: GOMES, W. B. (Org.). Psicologia no estado do Rio Grande do Sul. Porto Alegre: Museu Virtual da Psicologia. Local: editora, 2006. p. 25-55.

LIMA, N. R. L. B. As mulheres nas ciências: o desafio de uma passagem... A passagem do privado para o público. In: COSTA, A. A. A.; SARDENBERG, C. M. B. (Org.). Feminismo, ciência e tecnologia. Salvador: UFBA, 2002. p. 51-64.

MEADOWS, A. J. A comunicação científica. Brasília, DF: Briquet de Lemos/Livros, 1999. 
MOTT, M. L. O curso de partos: deve ou não haver parteiras? Cad. Pesquisa, São Paulo, n. 108, p. 133-160, 1999.

PINTO, C. Arthur Neiva: cientista e homem público. Rev. Med. Cir. Brasil., Rio de Janeiro, v. 11, n. 1, p. 3-11, 1932.

PORTO, F.; CARDOSO, T. A Luta das parteiras diplomadas pela prática da obstetrícia no Rio de Janeiro (Brasil). Enfermería Global, v. 15, p. 1-6. Feb., 2009.

RODRIGUES, J. G. Espelho do tempo: análise da coleção de obras raras da Fundação Oswaldo como fonte de pesquisa para Ciência Moderna. 1996. 148 f. Dissertação (Mestrado em Ciência da Informação) - Universidade Federal do Rio de Janeiro, IBICT, Rio de Janeiro, 1996.

RODRIGUES, A. H.; CALHEIROS, M. F.; COSTA, P. S. Análise bibliológica de livros raros: a preservação ao "pé da letra". Rio de Janeiro, 2006. Disponível em: <http://www.bn.br/planor/documentos/ARTIGOS/AnaliseBibliologica.pdf> . Acesso em 30 mar. 2013.

SANTOS, A. P. Histórias de cientistas e de comunidades científicas: memórias, documentos e performances de oralidades em História da Ciência. 2011. Disponível em: <http://www.sbhc.org.br/resources/anais/10/1345055908_ARQUIVO_arti gosbhccientistas.pdf $>$. Acesso em: 9 ago, 2013.

SILVA, F. F.; RIBEIRO, P. R. C. Mulheres na ciência: problematizando discursos e práticas sociais na constituição de mulheres-cientistas. In: CONGRESSO IBERO AMERICANO DE CIÊNCIA TECNOLOGIA E GÊNERO, 8., 2010, Curitiba. Anais... Curitiba: UTFPR, 2010.

SoUSA, A. M. C. Estudo de uma experiência de fluxo informacional científico no Instituto Oswaldo Cruz. 2006. 110f. Dissertação (Mestrado em Ciência da Informação) - Universidade Federal Fluminense, IBICT, Niterói, 2006.

SOUZA, R. S.; JACÓ-VILELA, A. M. Paixões e afetos: uma análise sobre conceitos e apropriações em tese de medicina do século XIX. Memorandum, Belo Horizonte, v. 15, p. 35-51, 2008.

STARLING, H. M. M.; GERMANO, L. B. P.; MARQUES, R. C. Medicina: história em exame. Belo Horizonte: Editora UFMG, 2011.

STEPAN, N. Gênese e evolução da ciência brasileira: Oswaldo Cruz e a política de investigação científica e médica. Rio de Janeiro: Fiocruz, 1976. 